\title{
Experimental and simulation study on steam gasification of phoenix-dactylifera date palm seeds
}

\author{
M.E. Babiker ${ }^{1,2, *}$, A.R.A. Aziz ${ }^{1,2}$, M. Heikal ${ }^{1,2}$, S. Yusup ${ }^{3}$ and F.Y. Hagos ${ }^{4}$ \\ ${ }^{1}$ Center for Automotive Research and Electric Mobility, \\ Universiti Teknologi PETRONAS, Tronoh, Malaysia \\ ${ }^{2}$ Department of Mechanical Engineering, \\ Universiti Teknologi PETRONAS, Tronoh, Malaysia \\ ${ }^{3}$ Department of Chemical Engineering, \\ Universiti Teknologi PETRONAS, Tronoh, Malaysia \\ ${ }^{4}$ Automotive Engineering Center, Faculty of Mechanical Engineering, \\ Universiti Malaysia Pahang, 26600 Pekan, Pahang, Malaysia \\ *Email: mohammedelamen@ gmail.com \\ Phone: +601121500059; Fax: +605-3654090
}

\begin{abstract}
To predict the performance of a fluidized bed gasifier (FBG) using date palm seeds (DPSs) as feedstock, a two-phase model was developed. The model simulates the hydrodynamic, kinetic reaction and steady state operations using the Aspen plus software. Experimental works were performed to study the effect of bed temperature, steam to biomass ratio, gas yield and carbon conversion efficiency. Six varieties of date palm seeds were studied: Deglet Nour (DN), Piarom (PI), Safawi (SA), Mabroom (MA), Suffry (SU), and Aliya (AL). The experimental data was used to validate the prediction model. Materials, process energy balances along with the minimization of free energy method were considered to measure the gas mole fraction. Different reactors of Aspen simulator, namely RYield, RGibbs and RCSTR plus MATLAB models were used to investigate the behaviour of DPSs in the FBG. The results confirmed that there were significant differences between all DPS varieties and treatments. The simulated results showed a good agreement with the experimental data. The gas yield (13.4\% increase), lower heating value $(11.9 \%$ increase), carbon conversion efficiency $(9.7 \%$ increase and steam decomposition (17\% increase) improved considerably with the rise of temperature from $730^{\circ} \mathrm{C}$ to $800^{\circ} \mathrm{C}$. Higher temperatures under steam gasification boosted the overall efficiency of the gasification process. $\mathrm{H}_{2}$ and $\mathrm{CO}$ production increased by as much as $35 \%$ and $29 \%$ (by volume) respectively at $800{ }^{\circ} \mathrm{C}$. $\mathrm{CH}_{4}$ contributed to the total yield of gas by a maximum of $13 \%$ and $15 \%$ for experimental and simulation works, respectively. $\mathrm{CO}_{2}$, on the other hand, showed a tendency to react positively (more than $50 \%$ of the total gas yield) at higher temperatures in both experimental and simulation studies.
\end{abstract}

Keywords: Aspen plus; Date Palm Seeds; fluidized bed gasifier; producer gas; steam gasification.

\section{INTRODUCTION}

Biomass is the fourth biggest source of energy in the world, providing about $35 \%$ of the main energy in developing countries and around 3\% in industrialized countries [1,2]. A wide range of biomass sources can be utilized to produce bioenergy in a diversity of 
forms. Due to the fact that more than $80 \%$ of the current energy demand is met by fossil energy sources, the global $\mathrm{CO}_{2}$ currently at $400 \mathrm{ppm}$ (annual average emission in the atmosphere) is far higher than the minimum safety threshold. On the other hand, energy security is the biggest challenge the world has faced, with the global population projected to reach 10 billion in 2050, which could cause the current energy demand to double [3]. Therefore, diversifying energy resources and particularly biomass will make it possible to ease the burden both on energy security and on global warming. Depending on their variety and quality grade, date seeds represent 6-12\% of the total date weight in the tamr ripening stage, i.e. around 901,064 to $1,802,128$ metric tons of date seeds were literally wasted or used in inefficient applications in 2008 and 2010 alone [4]. ASPEN (advanced system for process engineering) was developed at the Massachusetts Institute of Technology (MIT) under a United States Department of Energy project to simulate coal conversion processes [5]. It has now become a powerful tool for engineers to model chemical, power generation and other processes.

By developing a computer program, it may be feasible to solve a model structure of a chemical process with a small number of equations [6]. However, as the complexity of a plant integrated with several process units increases, solving a large equation set becomes a challenge. Many researchers have used the Aspen Plus simulator to measure mass and energy balances and to improve process designs [7]. An atmospheric circulating fluidized bed (CFB) gasifier was used and simulated in a model developed by [8]. Their study utilized Gibbs free energy minimization in combination with the restricted equilibrium method and validated it using experimental data. The method used specified temperatures of the gasifier reactions in order to predict the composition of the product gas, heating value, and conversion efficiency. A wide range of temperature, air preheating and equivalence ratios were applied to achieve the objectives of their study. The results revealed that the product gas composition, conversion efficiency and heating value were significantly affected by the variation of the above-mentioned parameters. Moreover, their findings indicated the range of temperature and ER in which high percentages of hydrogen and carbon monoxide are achievable. These results also showed that temperature and ER influenced the cold gas efficiency (CGE) and high heating value. Another study by the same authors [9] was to develop an original computer model of a preheating air CFB gasifier using Aspen Plus. However, their results showed that high ER reduced the gas-heating value, while air preheating increased $\mathrm{CO}$ and $\mathrm{H}_{2}$, and this in return increased the CGE and gas heating value. They reported the effectiveness of air preheating at low ERs. They further revealed that the steam agent had a good reactivity compared to that of fuel-bound moisture, as high moisture degraded the gasifier operation. A pre-drying process of the feedstock is required to avoid a loss of system efficiency. They concluded that the presence of steam is necessary to obtain a syngas with a high percentage of $\mathrm{H}_{2}$.

A biomass gasification model using dual fluidized bed (DFB) reactors was studied by [10-13]. The researchers used Aspen Plus and dedicated Fortran files to develop the model. The bed was separated into three modules based on the main chemical occurrence, namely biomass pyrolysis module, secondary reactions module, and char combustion module. They modelled permanent gases mass yields, species of 10 tar as well as char relating to the reactor temperature and pyrolysis correlation. Moreover, they modelled the second reaction using a semi-detailed kinetic approach to deal with the gas phase and catalytic conversion in the presence of $\mathrm{CH}_{4}$ char and tar species, i.e. benzene, phenol, naphthalene and toluene, the water-gas shift reaction, soot-steam gasification and char. The findings revealed that experimental data obtained from the two bed technologies were 
in agreement with the calculated results of gas compositions, flow rates, and lower heating values. Additionally, they indicated that the WGSR kinetic had a significant effect on the composition of gases and flow rates. They further optimized and reviewed WGSR and their kinetic laws.

Another model was developed by [14] to investigate the behaviour of the gasifier after reducing the moisture content and decomposing species into detailed yields. In their approach to predict the gasification process, they modelled the reactions using the Gibbs free energy minimization method. Temperature, biomass moisture content, equivalence ratio and steam injection were varied to study the effect of these parameters on the high heating value, cold gas efficiency and gas composition of biomass. They compared their simulation results with experimental data obtained from a hybrid biomass gasifier. The gasifier was fuelled with food, poultry and solid waste. The results showed that the increase in temperature increased the production of $\mathrm{CO}$ and $\mathrm{H}_{2}$, while the increase in ER reduced the existence of $\mathrm{CO}$ and $\mathrm{H}_{2}$ in the product gas and therefore reduced the CGE. The authors stated the moisture content as an influencing factor in terms of gas heating values. Moreover, they confirmed that the steam agent favours hydrogen production.

Murakami et al. [15] used a combination of a bubbling fluidized bed and a char combustor. The system was composed of a steam unit and silica sand bed with a capacity of 1.0 gram. The feedstock was dried coffee containing $10 \%$ water by weight in a batch feeding system. The simulation was performed at $800^{\circ} \mathrm{C}$ to represent the real condition of their particular gasifier. From observations, the pyrolysis process was able to convert more than $60 \%$ of feedstock carbon and as much as $75 \%$ of total feedstock mass into a product gas and char $(22 \%)$. Applying the previous outcomes of the gasifier as an input in Aspen software, the results showed that the dual bed gasifier could maintain the balance of heat and mass during the operation, and as a result, the cold gas efficiency might reach a higher level (more than 75\%). This efficiency is applicable if a suitable content of water is secured along the process and heat transferred from the gasifier and combustor is efficiently recovered within the system. They concluded that the time required for fuel reaction is less than 160 seconds when using a plug granular flow technique to calculate it.

The main purpose of this study is to develop a comprehensive simulation process of date palm seeds (DPSs) gasification in a pilot-scale fluidized bed gasifier to predict the syngas composition, performance and efficiency under different parameters and operating conditions. The study investigated the hydrodynamic and reaction rate kinetics, since thermodynamic equilibrium techniques are capable of measuring the effect of fuel and operating parameters on biomass. However, because the gasifier may not run under chemical or thermodynamic equilibrium, the maximum yield of desirable product gas using the Aspen Plus simulator without an optimized process model will give a reasonable prediction of gas compositions only. Therefore, a MATLAB model kinetic created in Aspen Plus software is a useful tool to develop a model to predict the effect of hydrodynamic and geometric parameters such as design parameters and the fluidizing velocity of the gasification process.

\section{METHODOLOGY}

\section{Experimental Setup and Procedures}

Experimental works were conducted using date palm seed (DPS) as a feedstock in a pilotscale gasifier for which the process flow diagram as shown in Figure 1. The works were performed using a pilot-scale gasification plant for creating a numerical work to predict 
the behaviour of the gasifier with different parameters and processes. Optimization of the parameters was taken into account to compute the overall and individual efficiencies of the gasifier's main components. The gasifier has two reactors $(250 \mathrm{~cm}$ height, 15 to 20 $\mathrm{cm}$ internal diameter) made of Inconel alloys and contains a bed material and uses steam as a fluidizing agent. The main components of the DPS gasification process are displayed in Figure 2. Six varieties of DPS from different regions, obtained from an importer in Penang, Malaysia, were characterized and tested in the gasifier. The DPSs were characterized for their ultimate and proximate analysis and the results were reported elsewhere [16].

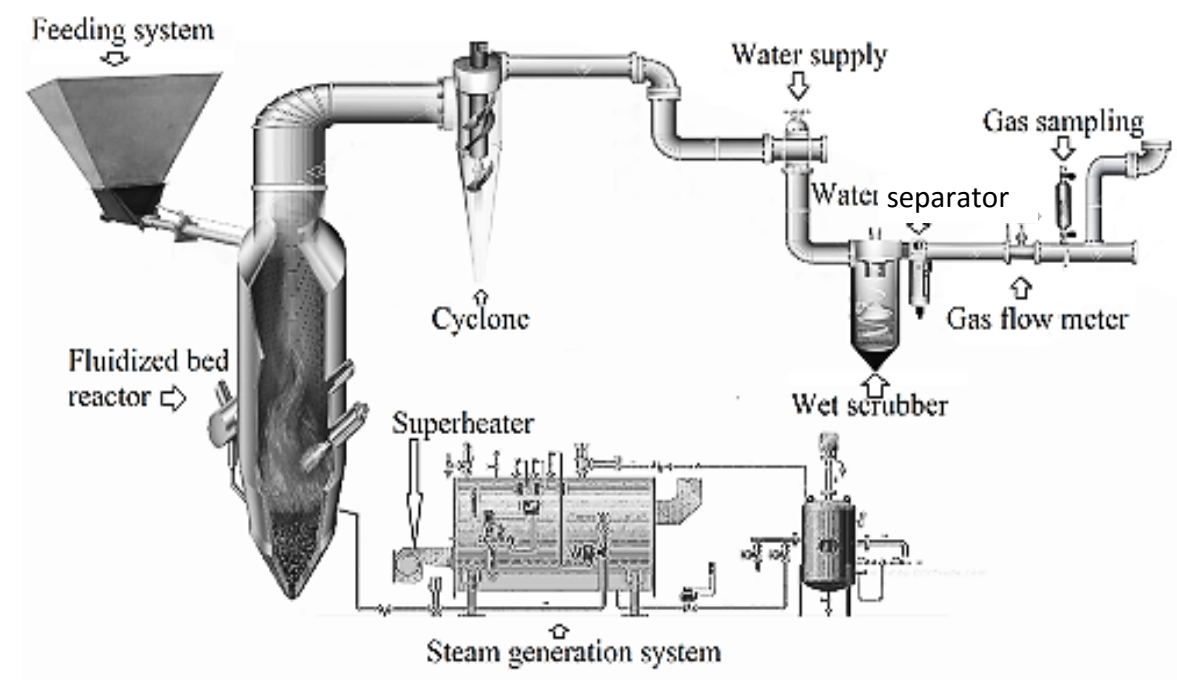

Figure 1. Fluidized bed components for DPS steam gasification system.

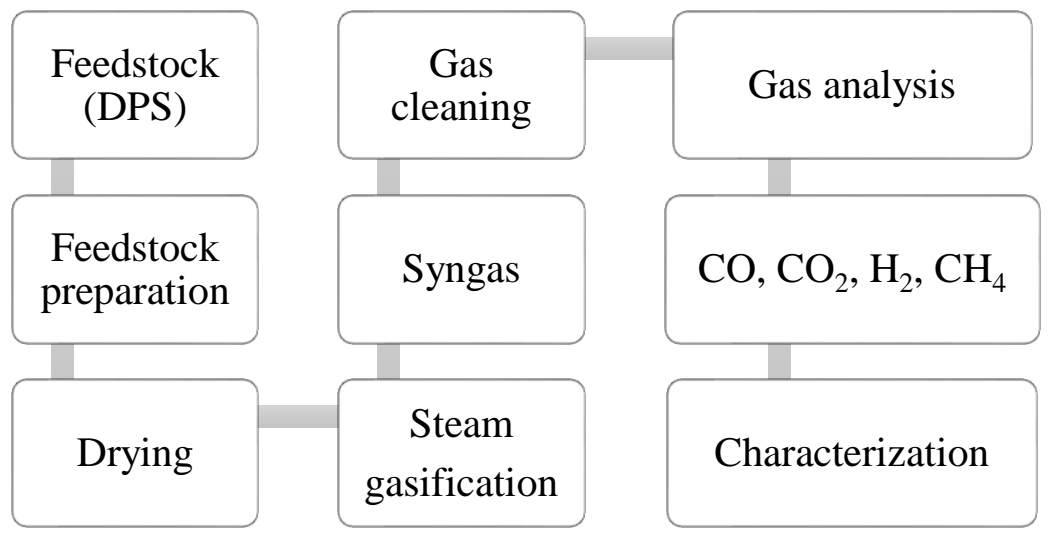

Figure 2. Schematic diagram of DPS gasification process.

\section{Modelling Works}

The models were developed using experimental results obtained from the gasifier. As the process of gasification engaged many parts and zones to consider, the model developed for this particular study mainly focused on the process of gasification. Figure 3 shows the Aspen Plus simulation diagram of the bed gasifier. The bubbling fluidized bed is composed of zones, i.e. a dense zone and freeboard zone, each with their own hydrodynamic properties. The dense zone is the place where the drying and devolatilization of the feedstock takes place and where superheated steam is injected at 
its lower boundary. Equations and correlation were used to calculate the local thermodynamic and hydrodynamics of the zone cells. However, the conservation equations of the carbon, bed material, and the energy of the whole of the zones were considered, instead of calculating the individual cells.

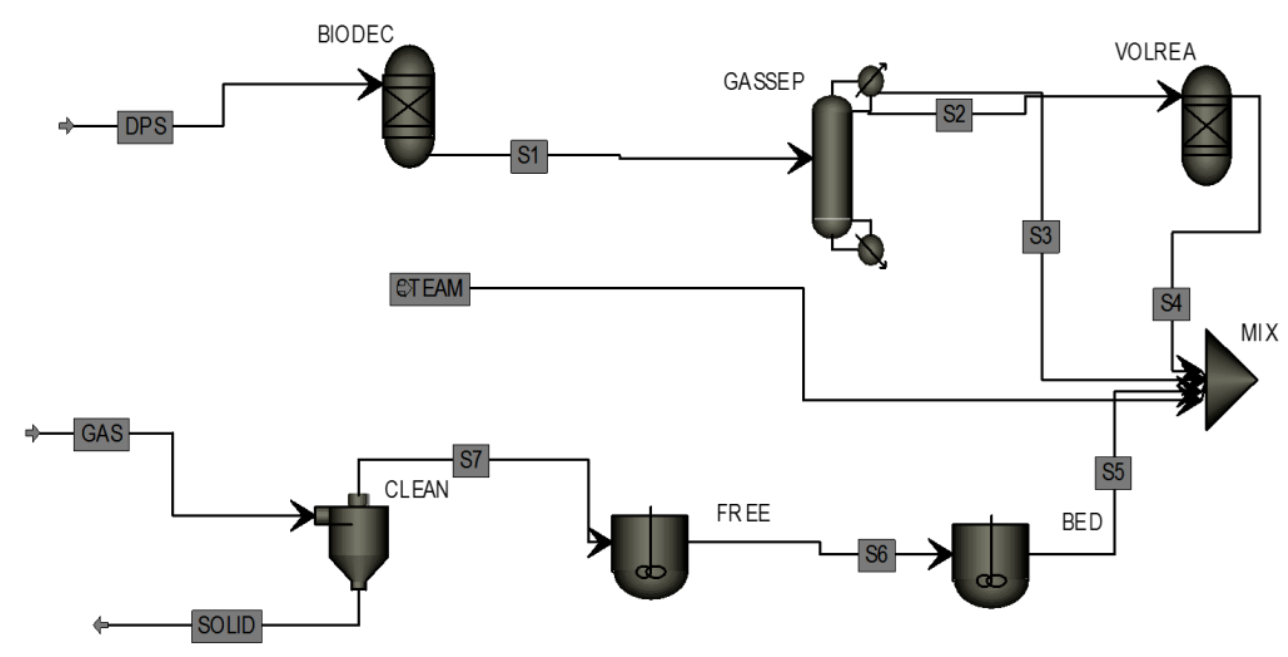

Figure 3. Aspen Plus simulation diagram of fluidized bed gasifier.

\section{Primary Assumptions}

In order to develop a model for predicting a steam-fluidized bed gasifier, the influence of hydrodynamic parameters on the DPS gasification in a fluidized bed and their kinetic reactions should be treated all together. The dense zone which represents the bubbling bed was modelled based on the modified two-phase theory, in which the bubbles size was considered as a function of the bed height. Moreover, all the bubbles were assumed to be of a uniform size. Therefore, the following valid assumptions should be applied to the Aspen Plus simulator in order to simulate the real operation [17]:

i). According to the shrinking core model in which the particle size and the reacting core shrink simultaneously, the average particle size is constant and of a uniform size and spherical shape.

ii). The distribution of gases within the emulsion phase (suspension of gas and solid around the bubbles and in the gasifier bed) is uniform.

iii). Gasification is in the steady state, i.e. all state variables are constant regardless of ongoing processes.

iv). The process is isothermal (uniform bed temperature).

v). DPSs have instantaneous devolatilization compared to char gasification.

vi). The product gas is composed mainly of $\mathrm{CO}, \mathrm{CO}_{2}, \mathrm{H}_{2}, \mathrm{CH}_{4}$ and water.

vii). The volatile products mainly consist of $\mathrm{CO}, \mathrm{H}_{2}, \mathrm{CO}_{2}, \mathrm{CH}_{4}$ and $\mathrm{H}_{2} \mathrm{O}$.

DPS char starts in the bed, is completed in the freeboard, and contains $\mathrm{C}$ and ash compound.

\section{Reaction Kinetics}

The heat produced in the combustion process during the gasification supports a series of endothermic reactions. Therefore, combustible gases such as hydrogen, methane and carbon monoxide are obtained through these reactions in three consecutive processes, 
namely pyrolysis, combustion and steam gasification. The reactions that occur during these processes are [18]:

$$
\begin{aligned}
& \mathrm{C}+x \mathrm{O}_{2} \rightarrow 2(1-x) \mathrm{CO}+(2 x-1) \mathrm{CO}_{2} \\
& \mathrm{C}+\mathrm{H}_{2} \mathrm{O} \rightarrow \mathrm{CO}+\mathrm{H}_{2} \\
& \mathrm{CO}+\mathrm{H}_{2} \mathrm{O} \rightarrow \mathrm{CO}_{2}+\mathrm{H}_{2} \\
& \mathrm{C}+2 \mathrm{H}_{2} \mathrm{O} \rightarrow \mathrm{CO}_{2}+2 \mathrm{H}_{2} \\
& \mathrm{C}+\mathrm{\beta H}_{2} \mathrm{O} \rightarrow(\beta-1) \mathrm{CO}_{2}+(2-\beta) \mathrm{CO}+\beta \mathrm{H}_{2}
\end{aligned}
$$

where $\alpha$ is a mechanism factor as described by Nikoo and Mahinpey [19] with the value of 0.5 to 1 for $\mathrm{CO}$ and $\mathrm{CO}_{2}$, respectively, assuming that char combustion forces $\mathrm{CO}$ or $\mathrm{CO}_{2}$ to leave the char particles.

As the char combustion is a very slow process compared to that of volatilization, there is sufficient time for the particles to spread around and burn in the bubbling bed. The char oxidation reaction takes place in the presence of oxygen and carbon on the char surface to form $\mathrm{CO}$ and $\mathrm{CO}_{2}$ [20]. Therefore, $\alpha$ is the link function between the gasification temperature and diameter (average) of the char particles. The amount of steam that is consumed during the reaction in Eq. (2) is represented by $(2-\beta) / \beta$, while the amount of steam that is consumed during the reaction in Eq. (4) is represented by $2(\beta$ 1) $/ \beta$. Researchers [21] managed to calculate the $\beta$ value as 1.5 to 1.1 when the temperature increased from 750 to $900^{\circ} \mathrm{C}$. In this study, and based on these values, $\beta$ was found to be in the range of 1.4 to 0.9 , which gave results in line with those obtained in the experimental work. As the conversion process of gas and solid is assumed to be in the steady state, it is unreasonable to use analytical analysis for nonlinear rate equations in a bubbling-bed model [22]. Therefore, numerical methods were developed in consecutive procedures to calculate the conversion. The methods used considered the level of solid conversion after its transit change, along with their corresponding gas phase concentration. The mass transfer rate of particles is inversely proportional to their sizes according to the basics of mass transfer; on the other hand, the particle size has no effect on the reaction rate. Moreover, the size of char decreases with the advancement of combustion. Therefore, the kinetic rate remains independent, while a clear increase in the mass transfer rate occurs. The following sequence of equations was described by [18] and modified by [19] to exemplify the reaction rate of the biomass:

$$
\begin{aligned}
\frac{d X_{c o}}{d t} & =k_{c o} \exp \left(\frac{-E_{c o}}{R T}\right) P_{O_{2}}^{n}\left(1-X_{c o}\right)^{2 / 3} \\
\frac{d X_{S G}}{d t} & =k_{S G} \exp \left(\frac{-E_{S G}}{R T}\right) P_{H_{2} O}^{n}\left(1-X_{S G}\right)^{2 / 3} \\
r C & =\left(\frac{d X_{C O}}{d t}+\frac{d X_{S G}}{d t}\right) \times \frac{\rho_{C} \varepsilon_{S} Y_{C}}{M_{C}}
\end{aligned}
$$

where $n$ equals 0.1 according to calculations made in [23]. However, some researchers reported different values for $n$; the actual value of $n$ should be within the range of 0.9 to 1.0 in a steam partial pressure environment of 0.25 atm up to $0.8 \mathrm{~atm}$.

\section{Hydrodynamic Assumptions}

To simulate the hydrodynamics in Aspen Plus reactors, the following assumptions were considered $[17,24]$ :

i). The two parts of the bed reactor, namely the bed and freeboard must be simulated separately.

ii). All fluidization regimes are running in the bubbling condition. 
iii). According to the basic design of the fluidized bed gasifier, solid particles decrease as the height increases. This phenomenon is explained by the bubbles coalescing at the bed zone and the return of particles at the transfer-disengaging height of the bed.

iv). The height also positively affects the volumetric flow rate of gas in terms of yield.

v). The bed material, particles, char and ash are mixed flawlessly.

vi). Hydrodynamic parameters of the reactor with a finite number of equal elements are considered.

vii). No variation takes place in the reaction conditions of the gas and solid except in the axial direction as the bed is a one-dimensional path.

\section{Bed Hydrodynamics}

Minimum fluidization velocity:

The minimum fluidization velocity $\left(u_{m f}\right)$ is the gas superficial velocity when the bed starts fluidizing (the velocity at incipient fluidization) [25]. The Ergun equation represents $u$ by calculating a pressure drop in a packed bed as the gas flows through it.

$$
\frac{\Delta P}{h}=150 \frac{\left(1-\epsilon_{m f}\right)^{2}}{\epsilon_{m f}^{3}} \frac{\mu_{g} u_{m f}}{\left(\emptyset_{s} d_{p}\right)^{2}}+1.75 \frac{1-\epsilon_{m f}}{\epsilon_{m f}^{3}} \frac{\rho_{g} u_{m f}^{2}}{\emptyset_{s} d_{p}}
$$

where $\Delta P$ is the pressure drop through the bed, with a positive value and $\mathrm{h}$ represents the length of a fixed bed. $\rho g$ is the density of the gas, while $d p$ is the particle diameter. $\mu g$ is the viscosity of the fluid. $\phi_{s}$ is the particle sphericity, where $s$, is the surface area of a sphere (having the same volume as a particle) divided by the particle surface area.

When applying the Ergun equation, the minimum fluidization voidage $\left(\epsilon_{m} f\right)$ is required to solve the problem. Therefore, $\epsilon$ is usually considered within the range of 0.4-0.5. Researchers developed an expression along with different particle types and sizes to define this according to data obtained from experimental works. The descriptions are as follows:

$$
\begin{aligned}
& \frac{1-\epsilon_{m f}}{\emptyset_{s}^{2} \epsilon_{m f}^{3}} \cong 11 \\
& (10) \\
& \frac{1}{\emptyset_{s} \epsilon_{m f}^{3}} \cong 14
\end{aligned}
$$

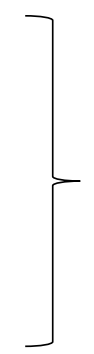

These descriptions are modified for the Ergun equation to obtain the Reynolds number at $\epsilon_{m f}$.

$$
R e_{p, m f}=\frac{d_{p} u_{m f} \rho_{g}}{\mu_{g}}=\sqrt{C_{1}^{2}+C_{2} A r}-C_{1}
$$

where

$$
A r=\frac{d_{p}^{3} \rho_{g}\left(\rho_{s}-\rho_{g}\right) g}{\mu_{g}^{2}}
$$


$G$ represents standard gravity and $\rho S$ is the density of the bed material. $C_{l}=33.7$ and $C_{2}=0.0408$, or instead $C_{1}=27.2$ and $C_{2}=0.0408$.

The following equation was introduced to calculate the minimum fluidization velocity for fine particles:

$$
\begin{aligned}
& u_{m f}=\frac{33.7 \mu}{\rho_{g} d_{p}}\left(\sqrt{1+3.59 \times 10^{-5} \mathrm{Ar}}-1\right) \\
& A r=\frac{d_{p}^{3} \rho_{g}\left(\rho_{s}-\rho_{g}\right) g}{\mu^{2}} \\
& B=1.0+\frac{10.978\left(u-u_{m f}\right)^{0.738} \rho_{s}^{0.376} d_{p}^{1.006}}{u_{m f}^{0.937} \rho_{g}^{0.126}} \\
& \varepsilon_{b}=1-1 / B \\
& \varepsilon_{f}=\varepsilon_{b}+\left(1-\varepsilon_{b}\right) \varepsilon_{m f} \\
& \varepsilon_{f}=\varepsilon_{b}+\left(1-\varepsilon_{b}\right) \varepsilon_{m f} \\
& \varepsilon_{m f}=0.4 \\
& 1-\varepsilon_{f b}=\left(1-\varepsilon_{f}\right) \exp (-a z) \\
& a=\frac{1.8}{u}
\end{aligned}
$$

\section{RESULTS AND DISCUSSION}

\section{Effect of Temperature on Hydrogen Production}

The product gas composition of the experimental and simulation data vs three different temperatures $\left(540^{\circ} \mathrm{C}, 730^{\circ} \mathrm{C}\right.$ and $\left.800^{\circ} \mathrm{C}\right)$ is depicted in Figure 4. The results of $\mathrm{H}_{2}$ revealed that the simulation findings are considerably in line with those obtained from experimental data. However, the increase in $\mathrm{H}_{2}$ percentage at the experimental (EXP) axis vs. temperature (TEMP) is clear as it shows a sudden peak at the highest temperature $\left(800^{\circ} \mathrm{C}\right)$. Generally, DPSs were expected to show low percentages of $\mathrm{H}_{2}$ at lower temperature $\left(540^{\circ} \mathrm{C}\right)$; however, the predicted results revealed a tendency of this gas to form at a very similar level compared to higher temperatures. Despite the fact that DPSs are highly reactive and described by a high volatile content, this phenomenon could be a direct outcome of ignoring the tar and unburned hydrocarbon formation at low temperature [5]. The slope of the trend line to reflect the statistical trend of the $\mathrm{H}_{2}$ percentage in the two experimental and simulation methods further demonstrates this comparison.

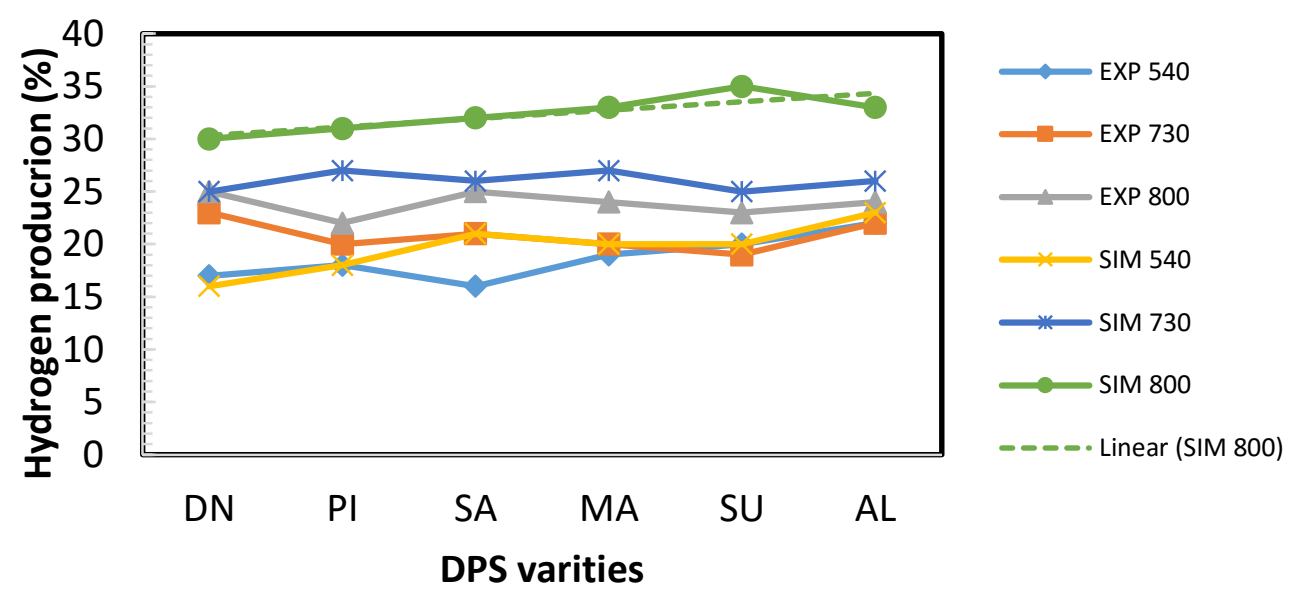

Figure 4. Effect of temperature on hydrogen production (volume \%). 


\section{Effect of Temperature on Methane Production}

Figure 5 shows the predicted trend of $\mathrm{CH}_{4}$ vs temperature. It is very clear that the simulation results correspond to those of the experimental data. $\mathrm{CH}_{4}$ decreased with the increase of temperature in almost all the varieties except for $730^{\circ} \mathrm{C}$, where some disagreement with the general trend was observed in the experimental curves. This decrease in $\mathrm{CH}_{4}$ production could be due to the shift in the reaction of methane reforming, as higher temperatures act as an endothermic reformer, according to dynamic equilibrium, to produce a higher percentage of char and therefore lower $\mathrm{CH}_{4}$ production [26]. On the other hand, the methanation reaction is the controlling factor of $\mathrm{CH}_{4}$ formation in the producer gas. This reaction is exothermic, which means that lower temperatures are thermodynamically favoured for $\mathrm{CH}_{4}$ production.

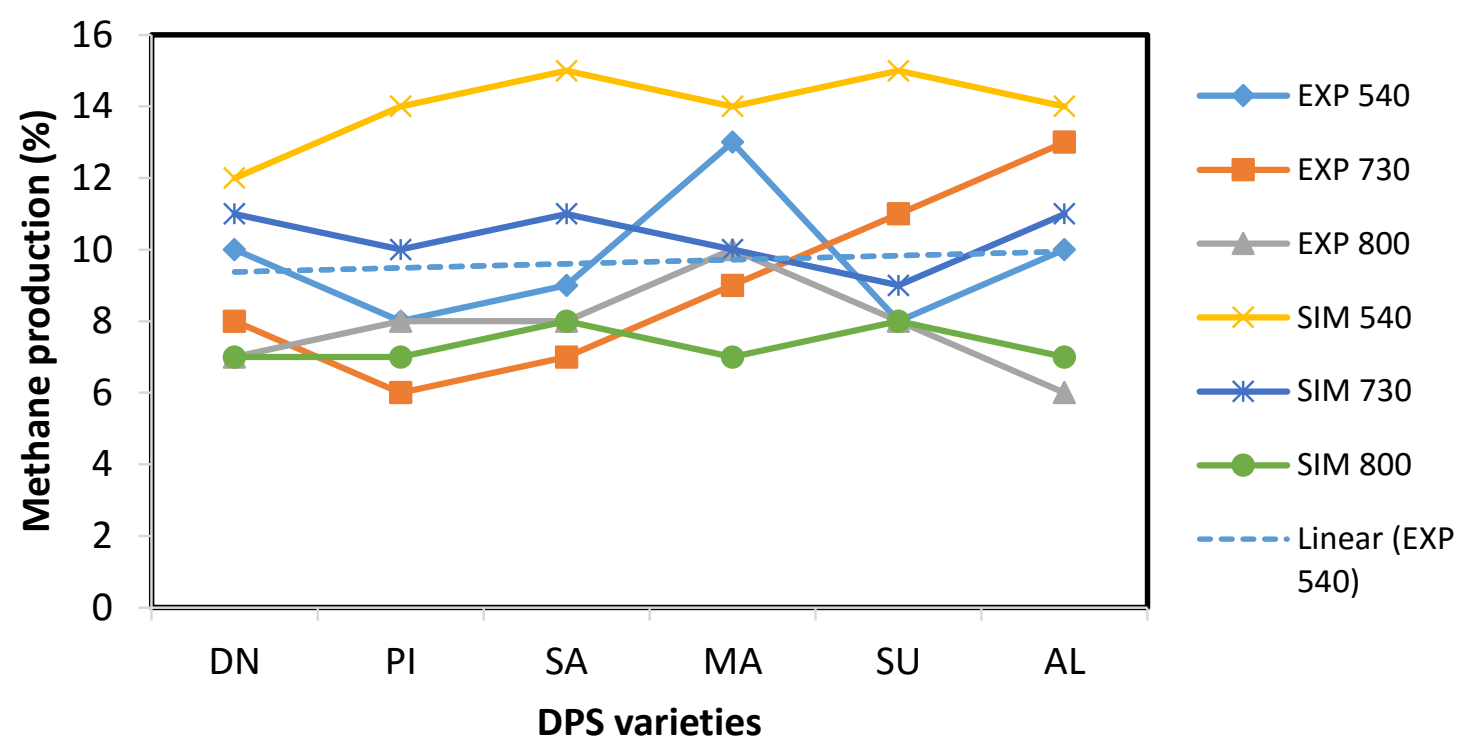

Figure 5. Effect of temperature on methane production (volume \%).

\section{Effect of Temperature on Carbon Monoxide}

The results shown in Figure 6 represent a related behaviour to the production of carbon monoxide versus the change in temperature. However, the $730^{\circ} \mathrm{C}$ and $800^{\circ} \mathrm{C}$ temperatures were different from the experimental readings in predicting a regular pattern through all the curves of the varieties except for DN and AL. These different findings might be attributed to the uncontrolled treatments and parameters at high temperatures, as well as to the control limits of the gasifier at maximum running conditions. Moreover, DN and AL, to some extent, have different thermochemical characteristics in terms of heating value and density compared to the other varieties. Nevertheless, the amount of emitted carbon monoxide decreased when the temperature was increased, and the MA variety showed less variation in both the experimental and simulated results. In general, the increase in CO content could be attributed to the effect of the increased DPSs moisture steam. Following these abrupt initial concentration trends, there is a continued gradual shift from carbon monoxide to hydrogen and carbon dioxide production, which indicates that the water-gas shift reaction rate, which is favoured in steam reforming, is relatively slow. 


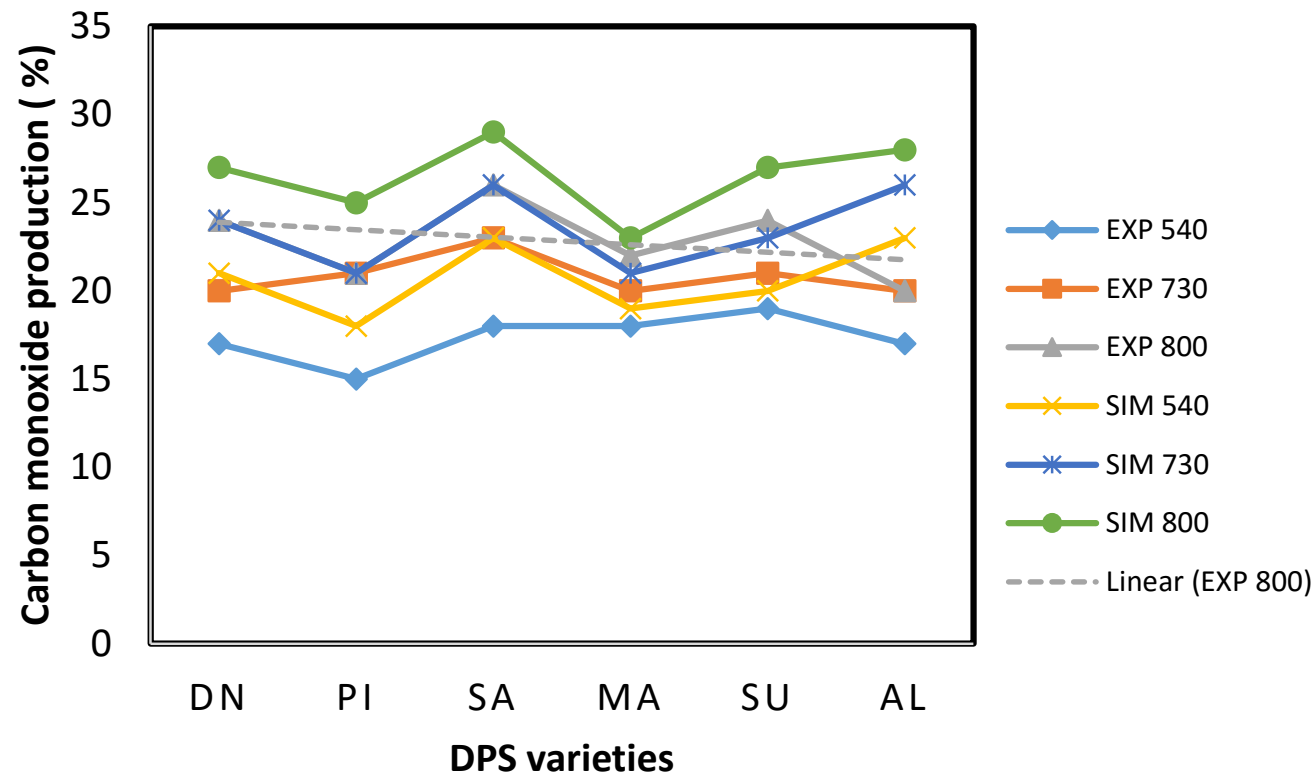

Figure 6. Effect of temperature $\left({ }^{\circ} \mathrm{C}\right)$ on carbon monoxide production (volume \%).

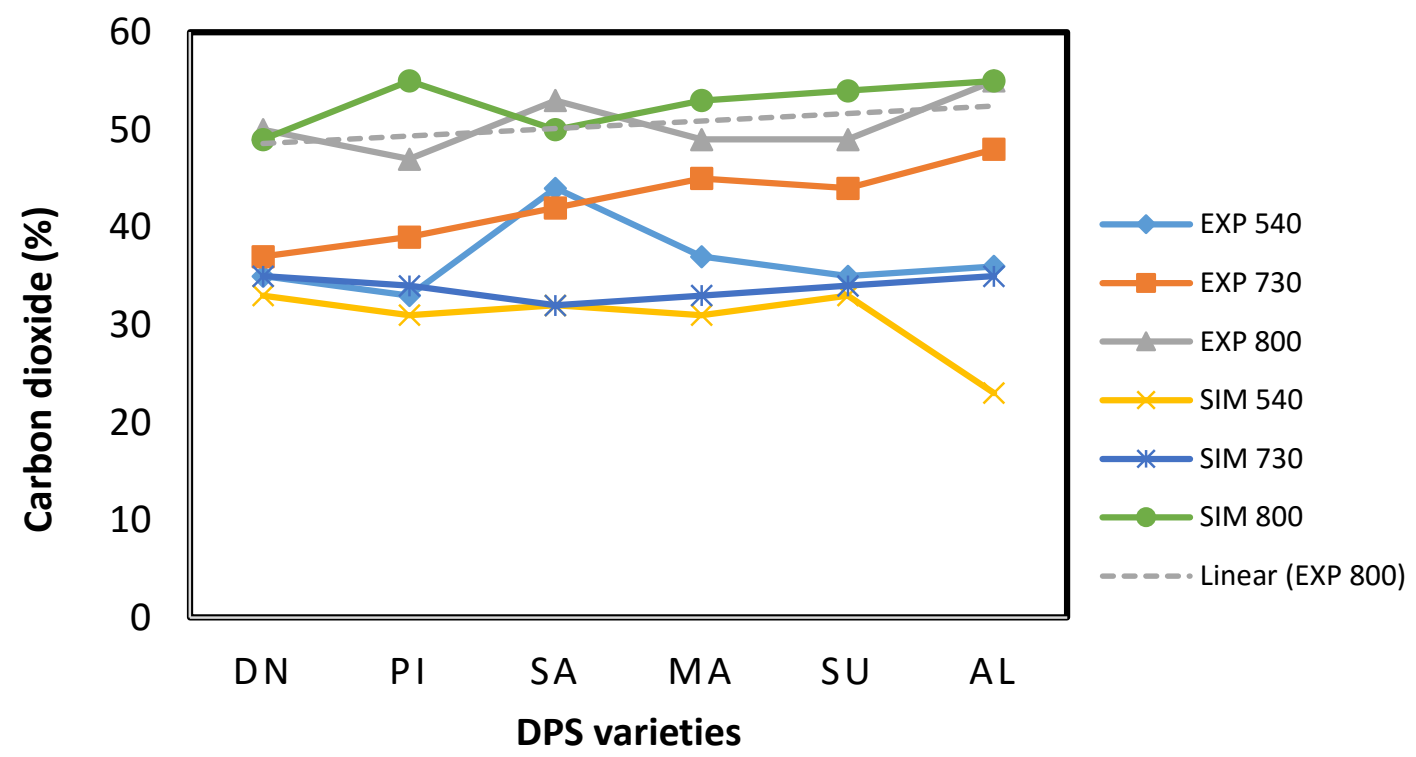

Figure 7. Effect of temperature $\left({ }^{\circ} \mathrm{C}\right)$ on carbon dioxide production (volume \%).

\section{Effect of Temperature on Carbon Dioxide Production}

The influence of temperature on carbon dioxide production is displayed in Figure 7. The figure represents the coherence between the simulated curves and the experimental data. Obviously, the predicted behaviour of this compound shows that the formation of $\mathrm{CO}_{2}$ favoured the higher temperatures, which could be due to gasification backward reactions, as is the case with the experimental results. This result might also be as a spontaneous reaction to the oxidation of DPSs by oxygen elements associated with the steam agent. During the oxidation, a great amount of heat is released; however, $\mathrm{CO}$ will be produced as a result of the partial oxidation that takes place due to the substoichiometric condition, which generates CO. Furthermore, fuel conversion at lower temperatures is noticeable 
compared to higher temperatures $\left(730\right.$ and $\left.800^{\circ} \mathrm{C}\right)$. In fact, $\mathrm{CO}_{2}$ acts as a gasification reactant to reduce the amount of char in the process. It is nevertheless 4-100 times slower in syngas production compared to steam gasification only [22, 26, 27]. These findings lead the researchers to conclude that $\mathrm{CO}_{2}$ acts as a diluent to the product gas. It can also be supported by the clear reduction in combustible gases $\left(\mathrm{CO}, \mathrm{H}_{2}\right.$ and $\left.\mathrm{CH}_{4}\right)$ in this study, especially at lower temperatures.

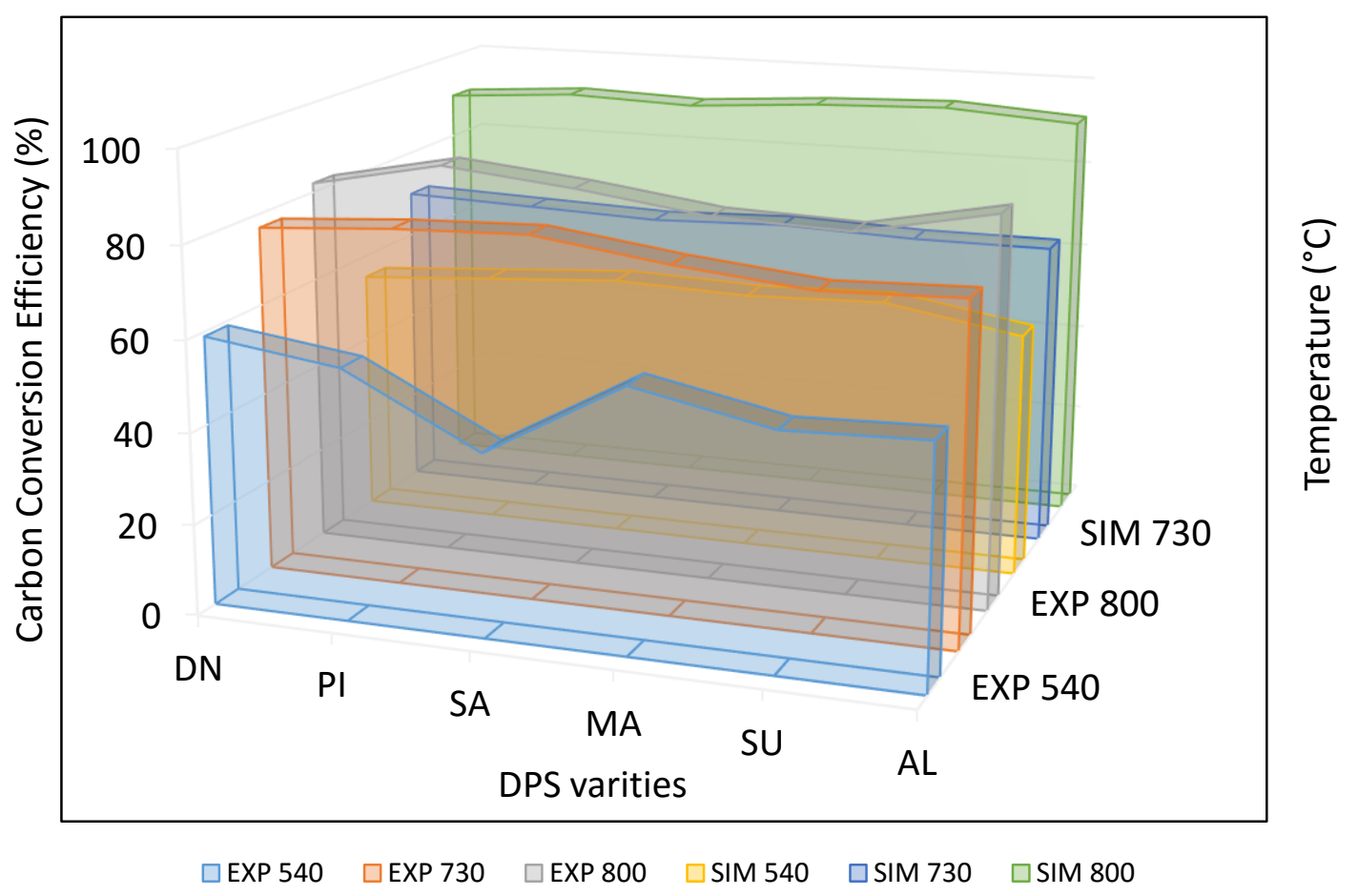

Figure 8. Effect of temperature on carbon conversion efficiency (\%).

\section{Carbon Conversion Efficiency and Syngas Production}

The results of carbon conversion efficiency and syngas production vs temperature are displayed in Figure 8 and Figure 9. The fluidized bed gasifier has the advantage of being very well mixed and having a high rate of heat transfer, resulting in uniform bed and freeboard conditions and significant tar cracking [28]. However, higher temperatures are an influencing factor too, as the predicted and experimental charts confirmed the increasing tendency of this parameter across all the varieties tested. In fact, unlike partial oxidation, in which the gasification efficiency can reach up to $95-99 \%$, the efficiency of the indirect-heat steam gasifier is limited to only 60-75\% [29] in the temperature range from 790 to $870^{\circ} \mathrm{C}$. In this study, the results obtained for the carbon conversion efficiency, for both experimental and simulation methods, showed good agreement with this report, as the temperature range was intentionally extended to accommodate a lower temperature $\left(540^{\circ} \mathrm{C}\right)$, which is out of the ideal temperatures for a bubbling fluidized bed gasifier. However, the lower temperature favours the formation of $\mathrm{CO}$, which is an advantage to be considered regarding syngas quality. 


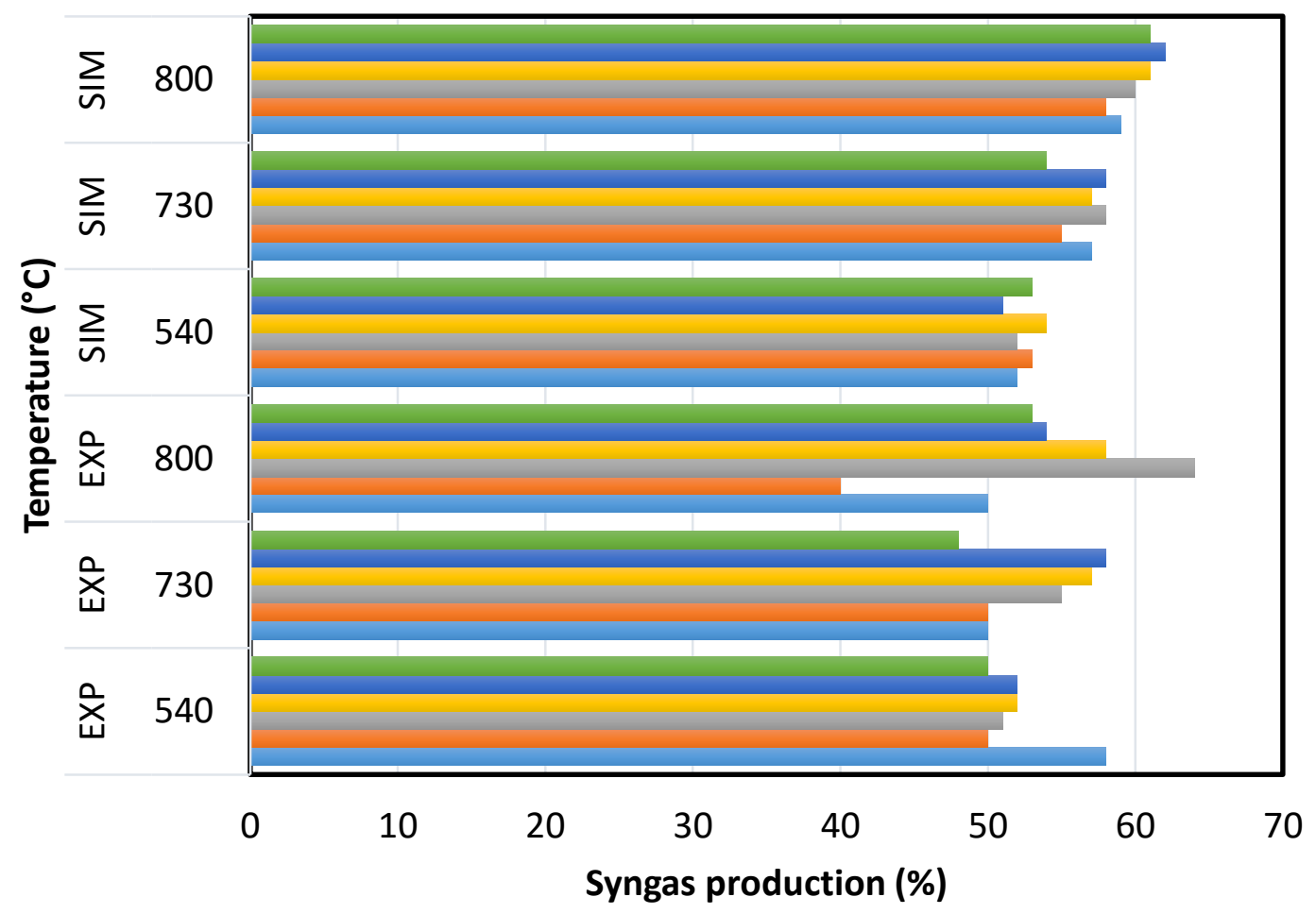

$\square \mathrm{AL} \square \mathrm{SU} \square \mathrm{MA} \square \mathrm{SA} \square \mathrm{PI} \square \mathrm{DN}$

Figure 9. Effect of temperature on syngas production (vol. \%).

\section{CONCLUSIONS}

An Aspen Plus model was developed to predict the behaviour of DPSs in a fluidized bed gasifier. Steady state operation under atmospheric conditions was assumed to build the simulation database. The kinetics reactions and hydrodynamics of the bed and freeboard were considered for an accurate prediction. The model was in good agreement with the experimental findings in confirming the following conclusions:

1. Using date palm seeds in a fluidized bed gasifier with steam as a gasifying agent at higher temperature (above $700^{\circ} \mathrm{C}$ ) and $1-1 \mathrm{~S} / \mathrm{B}$ mass ratio can significantly increase the efficiency of the overall process. The pyrolysis temperature, namely $540^{\circ} \mathrm{C}$, was found to have a significant influence on determining the amount of combustible gases. The highest yield of $\mathrm{H}_{2}(35 \%)$ was obtained for the SU variety at a simulated $800^{\circ} \mathrm{C}$, while the lowest yield $(16 \%)$ was observed for both DN and $\mathrm{SA}$, at experimental and simulated $540^{\circ} \mathrm{C}$ temperatures. Methane production reached the peak $(15 \%)$ under the simulated $540^{\circ} \mathrm{C}$ and dropped to the lowest level $(6 \%)$ and $(7 \%)$ when the temperature was set to an experimental and simulated value of $800^{\circ} \mathrm{C}$, respectively. Moreover, variation of $\mathrm{CH}_{4}$ production with temperature was evident for all varieties in both the experimental and simulated methods. The maximum production (29\%) of $\mathrm{CO}$ was recorded at a simulation temperature of $800^{\circ} \mathrm{C}$; however, the percentage difference with the experimental level $(26 \%)$ represents only a $10 \%$ reduction. The lowest value difference between $\mathrm{CO}$ production $(15 \%)$ was nearly $16 \%$ lower for the simulated $540^{\circ} \mathrm{C}$ temperature compared to $18 \%$ of the experimental $540^{\circ} \mathrm{C}$ temperature. Maximum $\mathrm{CO}_{2}$ was 
recorded at $55 \%$ production, for the $\mathrm{PI}$ and $\mathrm{AL}$ varieties under the simulated $800^{\circ} \mathrm{C}$ temperature, while the lowest value for $\mathrm{CO}_{2}, 23 \%$, was observed at the simulated $540^{\circ} \mathrm{C}$ only.

2. The gas yield, lower heating value, carbon conversion efficiency and steam decomposition improve considerably with the increase of temperature.

3. The current study introduced a new type of biomass waste, DPS, as a promising source of syngas production. The methods employed can be further adapted to predict the behaviour of a wide range of gasifier feedstocks.

\section{ACKNOWLEDGEMENTS}

The author would like to thank Universiti Teknologi Petronas for providing him the opportunity to pursue his study in an excellent work environment and continuous financial support under URIF 6/2012 project.

\section{REFERENCES}

[1] Omer AM. Built environment: Relating the benefits of renewable energy technologies. International Journal of Automotive and Mechanical Engineering. 2012;5:561-75.

[2] Demirbas MF, Balat M, Balat H. Potential contribution of biomass to the sustainable energy development. Energy Conversion and Management. 2009;50:1746-60.

[3] Fischer G, Schrattenholzer L. Global bioenergy potentials through 2050. Biomass and bioenergy. 2001;20:151-9.

[4] Babiker ME, Aziz ARA, Heikal M, Yusup S. The pyrolysis behavior of evolved species from date palm seeds. MATEC Web of Conferences: EDP Sciences; 2014. p. 06008.

[5] Mansaray K, Al-Taweel A, Ghaly A, Hamdullahpur F, Ugursal V. Mathematical modeling of a fluidized bed rice husk gasifier: Part I-Model development. Energy Sources. 2000;22:83-98.

[6] Jana. Process Simulation and control using Aspen: Prentice-Hall Of India; 2009.

[7] Keche AJ, Gaddale APR, Tated RG. Simulation of biomass gasification in downdraft gasifier for different biomass fuels using ASPEN PLUS. Clean Technologies and Environmental Policy. 2015;17:465-73.

[8] Doherty W, Reynolds A, Kennedy D. Simulation of a circulating fluidised bed biomass gasifier using ASPEN Plus: a performance analysis. 2008.

[9] Doherty W, Reynolds A, Kennedy D. The effect of air preheating in a biomass CFB gasifier using ASPEN Plus simulation. Biomass and Bioenergy. 2009;33:1158-67.

[10] Abdelouahed L, Authier O, Mauviel G, Corriou J-P, Verdier G, Dufour A. Detailed modeling of biomass gasification in dual fluidized bed reactors under Aspen Plus. Energy \& Fuels. 2012;26:3840-55.

[11] Al-Kayiem HH, Md Yunus Y. Drying of empty fruit bunches as wasted biomass by hybrid solar-thermal drying technique. Journal of Mechanical Engineering and Sciences. 2013;5:652-61.

[12] Muda N, Boosroh MH. Gasification of coal-petcoke blends in a pilot scale gasification plant. International Journal of Automotive and Mechanical Engineering. 2013;8:1457-66. 
[13] Sulaiman SA, Mat Razali NH, Konda RE, Atnaw SM, Moni MNZ. On the diversification of feedstock in gasification of oil palm fronds. Journal of Mechanical Engineering and Sciences. 2014;6:907-15.

[14] Ramzan N, Ashraf A, Naveed S, Malik A. Simulation of hybrid biomass gasification using Aspen plus: A comparative performance analysis for food, municipal solid and poultry waste. Biomass and Bioenergy. 2011;35:3962-9.

[15] Suda T, Murakami T, Aoki S, Matsuzawa Y, Xu G, Tani H. Biomass gasification in dual fluidized bed gasifier. Challenges of Power Engineering and Environment: Springer; 2007. p. 1213-7.

[16] Babiker ME, Aziz ARA, Heikal M, Yusup S. Pyrolysis characteristics of Phoenix dactylifera date palm seeds using thermo-gravimetric analysis (TGA). International Journal of Environmental Science and Development. 2013;4:521.

[17] Sadaka SS, Ghaly A, Sabbah M. Two phase biomass air-steam gasification model for fluidized bed reactors: Part I-model development. Biomass and bioenergy. 2002;22:439-62.

[18] Lee JM, Kim YJ, Lee WJ, Kim SD. Coal-gasification kinetics derived from pyrolysis in a fluidized-bed reactor. Energy. 1998;23:475-88.

[19] Nikoo MB, Mahinpey N. Simulation of biomass gasification in fluidized bed reactor using ASPEN PLUS. Biomass and Bioenergy. 2008;32:1245-54.

[20] Basu P. Combustion and gasification in fluidized beds: CRC press; 2006.

[21] Matsui I, Kunii D, Furusawa T. Study of fluidized bed steam gasification of char by thermogravimetrically obtained kinetics. Journal of chemical engineering of Japan. 1985;18:105-13.

[22] Timmer KJ. Carbon conversion during bubbling fluidized bed gasification of biomass: ProQuest; 2008.

[23] Dutta S, Wen C. Reactivity of coal and char. 2. In oxygen-nitrogen atmosphere. Industrial \& Engineering Chemistry Process Design and Development. 1977;16:31-7.

[24] Berruti F, Pugsley T, Godfroy L, Chaouki J, Patience G. Hydrodynamics of circulating fluidized bed risers: a review. The Canadian Journal of Chemical Engineering. 1995;73:579-602.

[25] Punčochář M, Drahoš J, Čermák J, Selucký K. evaluation of minimum fluidizing velocity in gas fluidized bed from pressure fluctuations. Chemical Engineering Communications. 1985;35:81-7.

[26] Donolo G, De Simon G, Fermeglia M. Steady state simulation of energy production from biomass by molten carbonate fuel cells. Journal of Power Sources. 2006; 158:1282-9.

[27] Butterman HC, Castaldi MJ. Influence of $\mathrm{CO}_{2}$ injection on biomass gasification. Industrial \& Engineering Chemistry Research. 2007;46:8875-86.

[28] Liu G, Vimalchand P, Peng W. Second stage gasifier in staged gasification and integrated process. Google Patents; 2015.

[29] Stevens C, Brown RC. Thermochemical processing of biomass: conversion into fuels, chemicals and power: John Wiley \& Sons; 2011. 